\title{
Reply to letter to the editor regarding "Efficacy and safety of finerenone in patients with chronic kidney disease: a systematic review with meta-analysis and trial sequential analysis"
}

\author{
Zhangning Fu ${ }^{1,2}$, Xiaodong Geng ${ }^{1,2}$, Kun Chi ${ }^{1,2}$, Chengcheng Song ${ }^{1,2}$, Di Wu ${ }^{2}$, Chao Liu ${ }^{2}$, Quan Hong ${ }^{2}$ \\ ${ }^{1}$ Medical School of Chinese PLA, Beijing, China; ${ }^{2}$ Department of Nephrology, Chinese PLA General Hospital, Chinese PLA Institute of \\ Nephrology, State Key Laboratory of Kidney Diseases, National Clinical Research Center for Kidney Diseases, Beijing Key Laboratory of Kidney \\ Diseases, Beijing, China \\ Correspondence to: Quan Hong; Chao Liu. Department of Nephrology, Chinese PLA General Hospital, Chinese PLA Institute of Nephrology, State \\ Key Laboratory of Kidney Diseases, National Clinical Research Center for Kidney Diseases, Beijing Key Laboratory of Kidney Diseases, 28 Fuxing \\ Road, Beijing 100853, China. Email: redhq@163.com; chaoliu301@foxmail.com. \\ Response to: Qiu M, Zhao LM. Long-term cardiorenal efficacy of finerenone in patients with chronic kidney disease and type 2 diabetes. Ann Palliat \\ Med 2021. doi: 10.21037/apm-21-2590.
}

Submitted Sep 24, 2021. Accepted for publication Oct 10, 2021.

doi: 10.21037/apm-2021-07

View this article at: https://dx.doi.org/10.21037/apm-2021-07

We would like to appreciate Qiu et al. taking an interest in our article (1) and their insightful comments.

In their letter, Qiu et al. mentioned that it would have made the results more perfect if we had assessed the longterm efficacy of finerenone on the cardiorenal endpoints in patients with chronic kidney disease (CKD) and included the latest cardiorenal outcome trial (CROT) of finerenone conducted by Pitt et al. (2021) (2). Therefore, they performed a further meta-analysis involving the studies of Pitt et al. (2) and Bakris et al. (3) to evaluate the longterm efficacy and safety of finerenone in patients with type 2 diabetes (T2D) and CKD.

As Qiu et al. pointed out, we agreed that the results of long-term cardiorenal efficacy of finerenone in Qiu et al.'s meta-analysis were more comprehensive since they not only included the latest trial of finerenone but also assessed both the long-term cardiorenal composite outcomes and the individual outcomes of finerenone. Although their findings suggested that finerenone could be used to improve longterm cardiovascular and renal prognosis in patients with $\mathrm{T} 2 \mathrm{D}$ and $\mathrm{CKD}$, evidence to reach this conclusion was far from sufficient because of the limited trials included in their meta-analysis. Thus, further studies are required to evaluate these outcomes.

There are also some issues we should clarify here. We have mentioned that finerenone might have a long-term benefit for patients with CKD in our previous meta-analysis (1) according to our included studies. We did not pool some of these individual long-term results owing to our deadline for retrieval and the limited quantity of included trials. In addition, our trial sequential analysis (TSA) results indicated that the cardiorenal efficacy and safety (including the shortterm and the long-term) of finerenone still need to be further proved.

To summarize, we appreciated the comments made by Qiu et al. and agreed with the conclusion they made that finerenone might be recommended in patients with T2D and CKD to improve their long-term cardiovascular and renal prognosis. However, due to the limited number of included studies, high-quality studies with larger sample sizes are still needed in the future to further confirm these results and reach a more convincing conclusion.

\section{Acknowledgments}

Funding: Fostering Fund of Chinese PLA General Hospital for National Distinguished Young Scholar Science Fund (2019-JQPY-002), National Natural Science Foundation of China (Nos. 81870491 and 82070741) and the National Key Research and Development Project (2018YFE0126600). 


\section{Footnote}

Provenance and Peer Review: This article was commissioned by the editorial office Annals of Palliative Medicine. The article did not undergo external peer review.

Conflicts of Interest: All authors have completed the ICMJE uniform disclosure form (available at https://dx.doi. org/10.21037/apm-2021-07). The authors have no conflicts of interest to declare.

Ethical Statement: The authors are accountable for all aspects of the work in ensuring that questions related to the accuracy or integrity of any part of the work are appropriately investigated and resolved.

Open Access Statement: This is an Open Access article distributed in accordance with the Creative Commons Attribution-NonCommercial-NoDerivs 4.0 International License (CC BY-NC-ND 4.0), which permits the non-

Cite this article as: Fu Z, Geng X, Chi K, Song C, Wu D, Liu C, Hong Q. Reply to letter to the editor regarding "Efficacy and safety of finerenone in patients with chronic kidney disease: a systematic review with meta-analysis and trial sequential analysis". Ann Palliat Med 2021;10(10):11242-11243. doi: 10.21037/ apm-2021-07 commercial replication and distribution of the article with the strict proviso that no changes or edits are made and the original work is properly cited (including links to both the formal publication through the relevant DOI and the license). See: https://creativecommons.org/licenses/by-nc-nd/4.0/.

\section{References}

1. Fu Z, Geng X, Chi K, et al. Efficacy and safety of finerenone in patients with chronic kidney disease: a systematic review with meta-analysis and trial sequential analysis. Ann Palliat Med 2021;10:7428-39.

2. Pitt B, Filippatos G, Agarwal R, et al. Cardiovascular Events with Finerenone in Kidney Disease and Type 2 Diabetes. N Engl J Med 2021. [Epub ahead of print]. doi: 10.1056/NEJMoa2110956.

3. Bakris GL, Agarwal R, Anker SD, et al. Effect of Finerenone on Chronic Kidney Disease Outcomes in Type 2 Diabetes. N Engl J Med 2020;383:2219-29. 